\title{
Çocuklara Yönelik Tüketim Alanı Olarak Yeni Medya: “Tippez Bizim Yerimiz” Örneğinde Bir İnceleme
}

\author{
Çilem Tuğba Akdağ \\ Deniz Elif Yavalar
}

\begin{abstract}
Öz
Küresel pazar koşullarına göre sürekli şekil değiştiren yeni medyada çocukluk: firmaların, ürün ve marka sadakati oluşturmak için çocukları cezbedecekleri argümanları keşfettikleri bir oyun alanına dönüşmüștür. Günümüzde çocuklar, dijital bir kültürün içine doğmakta, dijital kültürle büyümekte ve sosyalleşmektedirler. Dolayısıyla, yeni medyada çocuklara yönelik olduğu söylenen alanların ticarileşmesi, çocuk sitelerinin tüketim kültürü açısından incelenmesini daha da önemli kılmaktadır. Bu çalışmada, çocuklara yönelik internet sitelerindeki tüketim unsurlarını izlemek için, Türkiye'nin ilk ve tek çocuk ve gençlik portalı olduğu iddiasını taşıyan Doğan Yayın Grubuna ait olan "Tipeez Bizim Yerimiz” örneği üzerinden bir inceleme yapılmıştır. 2, 293, 531 kayıtlı kullanıcı sayısı bulunan, 6 farklı ülkede "Tweege" ismiyle yayınlanan Tipeez Çocuk ve Gençlik Portalı popüler bir çocuk sitesi olması nedeniyle inceleme için seçilmiştir. Çalışmanın ana sorunsalı, çocuklara yönelik hazırlanan site ve haber içeriği içinde doğrudan veya gizlenmiş olan tüketime ilişkin unsurların izlerini sürerek, çocukların şimdi ve gelecekte tüketim kültürünün nasıl potansiyel müşterileri haline dönüştürüldüklerinin ortaya çıkarılmasıdır.
\end{abstract}

Anahtar Kelimeler: Yeni Medya, Çocuk Pazarı, Tüketim Kültürü, Çocuk Siteleri.

\section{New Media As A Consumption Area For The Children: An Analysıs In The Case of "Our Place Tipeez"1}

\begin{abstract}
Childhood has transformed into a playground where companies discover arguments that are attractive to children to create product and brand loyalty in the new media, which constantly change shape in line with the conditions of the global market. Today, children are born into a digital culture, are growing and socializing with digital culture. Therefore, commercialization of the areas that are referred to be designed for children in the new media makes it more important to examine the kid-friendly websites in terms of consumer culture. "Tipeez Bizim Yerimiz" website belonging to Doğan Yayın Grubu, which is claimed to be Turkey's first and only child and youth portal, was examined for this study to monitor the consumption elements in the kid-friendly websites for children. Tipeez Children and Youth Portal, which has 2,293,531 registered users and is released under the name "Tweege" in 6 different countries, was selected for the study since it is a popular website for kids. The main question of the study was to find
\end{abstract}

1 "This study was presented on March 9-10 in "New Media Studies 3rd National Congress: New Media Focused on the Rights" Symposium but not published for the revision in full text. 
out how children are transformed into potential customers of the current and future consumption culture, by tracing the direct or hidden consumption-related elements within the website contents and the news prepared for children.

Keywords: New Media, Children's Market, Consumer Culture, Websites for the Children. 


\section{Giriș}

$\mathrm{D}$ avid Buckingham "Selling Childhood" (Çocukluğun Satışı, 2007) isimli makalesinde, çocuklara satış yapmanın yeni bir olgu olmadığını belirterek tarih alanındaki çalışmaların kitle iletişim araçlarının ortaya çıkışından itibaren çocukların potansiyel müşteriler olarak görülmeye başladığına işaret etmektedir. Bununla birlikte, yeni medyadaki olanakların gelişmesi çocuklara satış yapmanın farklı yollarını ortaya çıkarmışıı. Endüstri pazarının uzmanları, çocukları sadece yetişkin müşterilere ulaşmanın bir aracı olarak değil, aynı zamanda daha zeki bir biçimde serbest pazar ortamında çocuklara kendi haklarını özgürce kullanabileceklerini söyleyerek potansiyel müşteriler olarak onları da hedef almışlardır. Bununla birlikte gelişen "çocuk ve gençlik pazarı", çocukların giderek piyasa tarafından daha çok sömürüleceği düşüncesiyle endişe uyandırmaktadır (Buckingham, 2007: 15). Kapitalist pazar ekonomisi, bireylerin özgür seçim yapabilme miti üzerine dayanmaktadır. Endüstri pazarında birey aktif eyleyen bir yurttaş olarak istedikleri ürüne istedikleri zamanda ve biçimde ulaşma konusunda özgürdürler. Ancak söz konusu özgürlük "parası ve gücü" olanlar için bir özgürlüktür. Diğer taraftan kapitalist pazar ekonomisi metalaşmış ticari ürünlere sahip olma üzerine kurulmaktadır. Bu sistem içinde çocuk ya da erişkin olmanın bir önemi yoktur. Küreselleşen pazar endüstrisi, her yaşa göre ürün gamı sunarak potansiyel müşteri sayısını arttırabilme konusunda son derece becerikli ve demokratiktir.

Buckingham (2007: 15), iki farklı yaklaşımdan bahsetmektedir. İlki çocukları tüketim kültürünün pasif kurbanları olarak gören eleştirel teorilerdir. İkincisi ise, piyasanın çocukları daha aktif, tamamlanmış ve güçlü varlıklar olarak tanımladığı yaklaşımdır. Buckingham, eleştirel yaklaşımlara örnek olarak Naomi Klein'ın "Influential No Logo" (2001); Juliet Schor'un "Born to Buy" (2004); Susan Linn'in "Consuming Kids" (2004) ve Alissa Quart'ın "Branded" (2003) isimli kitapların öne çıktığını ifade etmektedir. Eleştirel yaklaşımlara göre, medya sunduğu içerikle cinselliğin, şiddetin, kötü beslenmenin, alkol ve içkinin toplumsal cinsiyetin, yanlış değerlerin yaygınlaşmasını neden olarak çocukların kişisel potansiyellerini arttırabilecek aktivitelere yönelmelerini engellemektedir. Söz konusu literatüre göre, medyanın çocuklar üzerinde zararlı etki ve sonuçları bulunmaktadır. Çocuklar, medya içeriğiyle yayılan tüketim kültürünün bombardımanı altında kalmaktadır.

Bugünkü gelinen noktada, çocukları internet gibi görece yeni iletişim araçlarından korumak ya da bu iletişim araçlarını kullanmalarına sınırlama koymak yeterli bir yöntem olarak görülmemektedir. Dünya'da ve Türkiye'de çocuk hak ve özgürlüklerini güvence altına almak için yapılan düzenlemeler, "çocuğa saygı kültürü", "kişisel hak ve özgürlükler", "çocuk haklarının öğretilmesi; bilim, sanat ve spor eğitimi" gibi esaslar üzerinedir. Bu kapsamda çocuklara güvenli çevrimiçi oyun, eğlenme, bilgi edinme ve yaratıcılığı geliştirme alanı sağlama amacıyla resmi çocuk portalı oluşturulması ve ülke çapında tanıtılması gibi girişimler "çocuk hak temelli" bir iletişim ortamının gerekli koşullarından biri olarak düşünülmektedir. Böylece çocukların bu yeni medya aracılığıyla kendileriyle ilgili konularda haberdar olabilecekleri, kişisel gelişimlerini sağlayabilecek içeriğe erişebilecekleri yeni bir mecraya kavuşacakları varsayılmaktadır.

Dijital medya araçlarının yaygınlık kazanmasının bir sonucu olarak ortaya çıkan ve içeriği kullanıcı tarafından üretilen web sitelerinin önemli bir parçasını çocuk web 
siteleri oluşturmaktadır. Akdağ (2016: 167), internet üzerinde çocuklara yönelik olarak hazırlanan web sitelerini üç başlık altında toplamıştır. Bunlar, çocukları eğlendirmeye ve bilgilendirmeye yönelik olduğu söylenen özel kuruluşların web siteleri, devlet kurumları tarafından kurulan çocuk siteleri ve tematik yayın yapan çocuk kanallarının devamı olan internet siteleridir. Bu çalışmanın haricinde, yeni medyada çocuk sitelerini araştıran çalışmaya rastlanılmadığı gibi internet mecrasında "çocuklara yönelik tüketim pazarı"nın Türkiye'de dinamiklerinin neler olduğunu araştıran herhangi bir çalışmaya da rastlanmamıştır. Çocukların ve gençlerin en çok tercih ettikleri mecralardan biri olan internet mecrasında daha küçüklükten itibaren kültürel olarak tüketim tohumlarının nasıl ekildiği şüphesiz son derece önemli ve bir o kadar da araştırılmaya muhtaç bir konudur. Tam da bu gereksinmeden doğan bu çalışmada, Türkiye'nin ilk ve tek çocuk ve gençlik portalı olduğu iddiasını taşıyan "Tipeez Bizim Yerimiz" isimli internet sitesi üzerinden çocukların yeni medyada nasıl birer tüketici yurttaş haline dönüştürüldükleri sorunsallaştırımıştır. Çalışmanın ilk kısmı olan kuramsal kısmında, tüketim kültürünün yeni bir mecrası olan internet pazarında çocuk ve tüketim ilişkisine değinilmiş, ardından "Tipeez Bizim Yerimiz" sitesini oluşturan unsurların "tüketim söylemi" açısından incelemesine geçilmiş ve son olarak ise sitede yayınlanan haberlerin içerik ve söylemlerine bakılarak tüketim ideolojisi üzerinden haber okuması yapılmıştır. Böylece, çocukların daha erken yaşlarda tüketim ideolojisiyle nasıl tanıştırıldığı; hangi unsurların söz konusu söylemin ekilmesinde etkili bir biçimde kullanıldığı araştırılmıştır.

\section{1. Çocukların Yeni Medya Kullanımı ve Tüketim Kültürü}

İnternet istatistiklerini düzenli olarak yayımlayan "InternetWorldStats.com"2 sitesinin rakamlarına göre, 2016 yılı itibarıyla dünyada yaklaşık 3,5 milyara yakın internet kullanıcısı bulunmaktadır. Yine "InternetLiveStats.com" sitesinin çeşitli internet firmalarının yıllık bilançolarına dayanarak yaptığı hesaplamalara göre ise, 2016 yılı nisan ayı itibarıyla dünyada 1 saniye içinde yaklaşık 7 bin tweet atılmakta, 54 bin Google araması yapılmakta, 120 bin YouTube videosu izlenmekte, 2,5 milyon e-posta gönderilmektedir. Internetteki tüm bu hareketlerin sonucunda 1 milyarı aşkın web sitesinden saniyede 34 bin gigabayt büyüklüğünde veri iletişimi yapılmaktadır (Polat, 2016: 411).

Bilgi Teknolojileri ve İletişim Kurumu (BTK) verilerine göre ise, Türkiye'de 48,3 milyon kişi internet kullanmaktadır (Bayzan, 2016: 2). Nisan 2016 Türkiye İstatistik Kurumu (TUIK) Hane Halkı Bilişim Teknolojilerini Kullanım Araştırması sonuçları, son 1 yıl içinde bilgisayar ve internet kullanım oranlarının, 16-74 yaş grubu dahilinde erkeklerde yüzde 64,1'den yüzde 70,5'e; kadınlarda ise yüzde 45,9'dan ve yüzde 51,9'a ulaştığını göstermektedir. Yine aynı araştırma sonuçlarına göre, incelenen örneklemde hanelerin yüzde 96,9'u cep telefonu veya akıllı telefondan, yüzde 25,6'sında sabit telefonundan; yüzde 22,9'unda masaüstü bilgisayarında, yüzde 36,4'ünde taşınabilir bilgisayarından internete bağlanmakta olduğu tespit edilmiştir (http://www. tuik.gov.tr/ Pre Haber Bul tenleri.do?id=21779). Çocukların internet kullanma durumlarıly ilgili araştırmalara bakıldığında ise internet kullanım oranının çok küçük yaşlarda başladığı görülmektedir. Dijital kültürle erken yaşlarda tanışan bu kuşak, Y kuşağı olarak da adlandırılmaktadır. Y kuşağı kavramına göre, 1979'dan sonrası doğan 60 milyon çocuk bu kuşak içinde değerlendirilmektedir. Y kuşağı çocukları ebeveynleri yeni medyayı anlamaya 
çalışırken, bizzat bu kültürün içine doğmaları nedeniyle onlara göre daha fazla interneti kullanmaktadırlar (Montgomery, 2000: 147). 2013 yılı itibariyle Amerikalılar'ın televizyon ve video izleyerek geçirdikleri zamanın, uykuda geçirdikleri zaman kadar olduğu tespit edilmiştir. Yine Amerikan Medikal Birliği'nin hazırladığı rapora göre, çocukların televizyon ve video başında geçirdikleri zamanın günlük yaşam aktiviteleri için geçirilen zaman dilimine göre büyük bir yer tuttuğu ifade edilmektedir (Hazen ve Winokur ,1997). Bryce'a göre (2005), bu istatistikler, Amerika'daki yıllık 263 milyon dolar reklam endüstrisi tarafından şekillendirilen televizyon programları aracılığıyla verilen mesajlar düşünüldüğünde endişeleri arttırmaktadır. Çünkü televizyon programları yoluyla işlenen tüketim mesajları sadece ürünlerin satışına değil aynı zamanda değerlerin, imajların ve kimliklerin genç insanlara nasıl "tüketici yurttaş" olabileceklerini öğretmeye hizmet etmektedir (Griox ve Pollock, 2011: 73-74).

2013 yılı Türkiye İstatistik Kurumu tarafından gerçekleştirilen Hane Halkı Bilişim Teknolojileri Kullanım Araștırması, ilk defa 6-15 yaş grubu çocukları da içerecek şekilde genişletilmiştir. Bu yaş aralığındaki çocukların bilgisayar kullanmaya başlama yaşı ortalama 8 ile 9 yaş arasındadır. Haftalık ortalama internet kullanım süreleri dikkate alındığında, 6-15 yaş grubundaki çocukların yüzde 38,2'si iki saate kadar; yüzde 47,4'ü üç ile on saat arasında, yüzde 11,8'i on bir ile yirmi dört saat arasında; yüzde 2,6'sı ise yirmi dört saatin üzerinde bilgisayar başında kalmışlardır (http:// www. tuik.gov.tr/PreHaberBultenleri.do?id=15866). Bir başka deyişle, Türkiye'de çocukların hiç de azımsanmayacak bir kısmı (yüzde 14,4'ü) on saatten fazla bilgisayarda zaman geçirmektedir.

EU Kids Online araştırma raporunda ise, çocukların interneti kendi odalarında kullanım oranlarının sürekli artış gösterdiği tespit edilerek, araştırmaya katılan 9-16 yaş arası bin çocuğun yüzde 85'nin interneti evde kullandığı görülmüştür. Aynı araştırmada, çocukların yüzde 10'unun mobil telefon üzerinden internet kullandığı tespit edilmiştir. Çocukların internet kullanım amaçlarının belirlenmesine yönelik bir araştırma da, "Mutlu Çocuklar Derneği” tarafından yapılmıştır. İlköğretim ve lise öğrencileri arasında yapılan araştırmaya göre, erkek öğrencilerin yüzde 68,2'si interneti daha çok oyun oynamak için kullanırken, kızların yüzde 50,8'inin interneti film izlemek veya müzik indirmek için kullandığı tespit edilmiştir (Temür, 2013: 23-24, 33).

Kâr arayışı peşinde olan reklamcıların, çocukları endüstri pazarının "yeni tüketicileri" olarak hedef almaya başlamaları erken pazarlama dönemine rastlamaktadır. Nitekim Murdock, Printer's Ink'in 1923yılında söylediği “Bugünün çocuğu yarının büyük müşterisi olacaktır" sözünü hatırlatarak çocuklara yönelik yeni oluşacak tüketim pazarına işaret etmiştir (Murdock, 2015: 10). Ancak, çocuk tüketim pazarı söz konusu dönemde henüz olgunlaşmamıştır. Pazarın olgunlaşarak istenilen kıvama gelmesi için II. Dünya Savaşı sonrası çocuk nüfusunun artması beklenmiştir. "Bebek Patlaması Kuşağı" olarak da adlandırılan 1950'li yıllar, ABD'de çocuklara yönelik pazarlama faaliyetleri açısından en yoğun dönem olarak bilinmektedir. Yine bu dönemde tipik orta sınıf ailenin hanesine çok farklı türde ve hacimde ürün girmiştir. II. Dünya Savaşı döneminde ve bu süreci izleyen elli yılda çok büyük ekonomik sıkıntılar çekilmiş ve çocuklara yönelik pazarlama faaliyetleri bu duruma paralel olarak giderek hız kazanmıştır (Engin, 2013: 218). Pazarlama kuramcıları, çocukların iki dünya savaşı arasındaki dönemde ortaya çıkmış olan ileri düzeyde gelişmiş kapitalist toplum içerisinde oluşmuş kitle tüketici sistemini 
şekillendiren en önemli güç olduğunu fark etmekte gecikmemişlerdir. Böylece firmalar ve reklamcılar açısından çocuklar, hem başıı başına büyüyen pazarın yeni tüketicileri hem de yetişkinlik döneminde taşıyacakları marka bağlıığı ve tüketici alışkanlığıyla sadık müşteriler olarak görülmeye başlayacaklardır (Murdock, 2015: 10).

Günümüzde ise gösteri ve eğlence endüstrisi içinde önemli ve stratejik bir yer tutan çocuklara yönelik üretilen çizgi filmler; bu ürünleri temsil eden figür ve oyuncaklar, kültürel bir mirası yansıtmaktan ziyade küresel bir sermaye tarafından tasarlanmaktadır. Ayrıca, çocukları hayata hazırlayıp, sorumluluk duygusu kazandırmaktan çok oyalanma ve zihinsel uzaklaşma yaratmaktadır (Taylan, 2015: 95). Çocukluğun topyekûn olarak kâr getiren bir pazar için ticari metaya dönüştürülmesi, çocuğun şimdiki ve gelecekteki pazarlar içerisinde "maddeci çocuk" imgesi etrafında kıstırılmış roller içerisinde yetişip büyümesini tertip etmiştir (Murdock, 2015: 9).

Elektronikli enformasyon ortamının çocukluğu ortadan kaldırdığını belirten Postman (1995: 14), çocukları simgeler ve elektriğin mucizesiyle herhangi bir yetişkinin bildiği her şeyi bildiğini vurgulayarak yetişkin ve çocukların davranış, dil, tutum ve arzularının hatta fiziksel görünümlerinin giderek artan bir biçimde birbirine benzediğini ve ayırt edilemediğini ifade etmektedir. Postman'ın burada vurgulamak istediği şey, yeni teknoloji içine doğan çocukların giderek endüstriyel pazar tarafından şekillendirilmiş içeriğe maruz kalarak, çocukluğun masumiyetini yitirmeleri ve giderek yetişkinlere benzetilmiş olduklarıdır.

Kültür endüstrisi içinde çocuk ve çocuk oyun algısı da değişme uğramıştır. Halk kültüründeki geleneksel çocuk oyunlarının yerini, sanal bir kültürün parçası olan dijital oyunlar almıştır. Dijital oyunlar, küresel anlamda gündelik tüketimci yaşamın en önemli metası haline dönüşmüştür (Çakır ve Yavalar, 2015: 659). Binark ve Bayraktutan Sütçü "Kültür Endüstrisi olarak Dijital Oyun" isimli kitaplarında dijital oyunları, 1980 'lerin ortasından itibaren bilgisayar oyunları, video oyunları, elektronik oyunlar şeklinde tanımlamıştır. Binark ve Sütçü (2008: 41), Türkiye'de yaygın olarak kullanılan tanımlamanın bilgisayar oyunları olduğunu belirterek bununla birlikte 2000'li yılların ortalarından itibaren dijital oyun kavramsallaştırmasının da kullanıımaya başlandığını söylemektedir. Yine aynı çalışmada, dijital oyun kavramsallaştırılması ile arcade (atari) oyunların, PC oyunlarının, konsol oyunlarının, mobil oyunların farklı ve tüm türlerini kapsadığından bahsedilmiştir. Buna göre bilgisayar oyunları, hem tematik hem de teknolojik özelliklerine göre ağ, aksiyon, macera, motor sporları-yarış, rol yapmacanlandırma oyunları, simülasyon, spor ve strateji oyunları olarak sınıflandırımıştır (Binark ve Bayraktutan-Sütcü, 2008: 41-43).

İnternetin hızla büyümesi, yeni bir dijital medya kültürünü ortaya çıkarmıştır. Gençler ve çocuklar, yetişkinlere göre bu yeni teknoloji tarafından daha hızla sarmalanmış durumdadır. İnternetin gittikçe yaygınlaşan bu artan gücüne bağlı olarak çocuklar ve gençler reklamcılar için pazarda önemli bir hedef-kitle haline gelmişlerdir. Bu yeni eğilimler özellikle çocuklara ve gençlere yönelik olarak tasarlanmış yeni web sitelerinin ve farklı yeni medya içeriklerinin giderek sayıca artan bir biçimde ortaya çıkması sonucunu doğurmuştur (Montgomery, 2000: 61). Böylece, pazarlama ve reklamcılık hızla çocuklara yönelik web sitelerinin içeriklerine sızmaya başlamıştır. Çocuklara reklam ve pazarlama yoluyla satış yapmanın farklı bir yolu olarak ortaya çıkan yeni 
medya, televizyondaki ticari reklam ve satışın teşvik edilmesi yöntemlerinden önemli ölçüde farklı bir yöne doğru kaymıştır. İnteraktif medya, içerik ve reklam arasındaki sınırları kıran bir dizi yeni iletişim teknikleri getirmiştir (Montgomery, 2000: 65).

Timisi'ye göre (2011: 143), aktiflik kavramı etkileşimle yer değiştirmiş, izleyici kavramı da kullanıcı halini almıştır. Artık bilgisayar ekranı karşısındaki çocuk "etkileşimci kullanıcı" olarak adlandırılmaktadır. Geleneksel iletişim araçları karşısında çocukların iletişim sürecine müdahaleleri sınırlıdır. İnternette ise geleneksel medyadan farklı olarak mesaj önceden belirli bir kaynak tarafından seçilip, hazırlanarak anında ve herhangi bir denetime tabii tutulmadan sunulmakta ve istenildiği zaman ulaşılabilmektedir. Bu anlamda internet: anonim, hızlı ve anında iletişime imkân vermiş ve çocukların kendilerini de bir içerik sağlayıcısı haline getirmiştir (Timisi, 2011: 143).

Gençlere yönelik pazarlamanın kârlı bir alan olarak görüldüğü çocuk endüstri pazarının, hali hazırda mevcudiyetiyle birlikte çocuklara yönelik hazırlanan dijital içeriğin ve hizmetlerin geliştirilmesi etkili olmuştur (Montgomery, 2000: 65). Ferrazzi ve Benezra'ya göre (2001) çocuklara internet reklamcılığıyla yiyecek ürünü satılmaya çalışılıyorsa, televizyon ya da yazılı basından farklı bir şekilde sergilenecektir. Bu bağlamda internet reklamcılığında, web sitesi çocukların katılımını sağlayabilecek oyun dolu bir tasarımla dizayn edilmeli ve buradaki anahtar kavram "ürün tutundurma" kavramı olmalıdır. İnternet sitesi üzerinden yapılan reklamda, çocukların hemen dikkatinin çekilmesine odaklanan, geleneksel medyanın aksine çocukların aktif bir şekilde katılıkları, isteklerine göre şekillenmiş bir içerik belirlenmektedir (Aaker, 2002).

Online pazarlamacılıkta kullanılan reklamların, sadece 30 saniyede çocukların dikkatini çekmeleri beklenememekte ve daha uzun dakikalarla onların dikkatini yakalamak amaçlanmaktadır. Internet üzerinden sunulan pazarlama mesajı web sitesindeki advergame (reklam-oyun) türündeki içerik ya da diğer aktivitelere iliştirilmiş olmalıdır (Montgomery, 2001; Moore, 2004). Pazarlama uzmanları, eğlence mecralarına reklam yerleştirmenin çocukların şüphe duymalarını azaltmanın ve marka mesajını iletmenin en açık ve en etkili yolu olduğunu iddia etmişlerdir (Lindstrom ve Seybold, 2003).

\section{Araștırmanın Varsayımları, Yöntemi ve Sınırlıııları}

Çocukların kendi sözlerini söyleyebilecekleri, eğitim, sosyalleşme ve bilgi alma gibi intiyaçlarını giderebilecekleri alternatif bir mecra olarak yeni medyanın önerilmesi, bu mecranın çocuklar için gerçekten faydalı bir alternatif olup olmadığı sorusunu da beraberinde getirmiştir. Geleneksel medyada kendisine bir yer bulamayan dezavantajlı gruplardan biri olarak görülen çocuklar, boş vakitlerini değerlendirmek amacıyla yeni medyada eğlenerek öğrenme vaadi taşıyan web sitelerine yönelmektedirler. Fakat çocuk endüstrisi ve çocuk pazarı geleneksel araçlarla birlikte bu yeni medya aracını da kendi amaçları doğrultusunda şekillendirmeye devam etmektedir. Bu çalışmada yeni medyada yaygınlığı ve ulaştığı kitle bakımından popüler bir web sitesi üzerinden "tüketim ideolojisinin çocuklara yönelik içerik üzerinden nasıl aktarıldığı ve yaygınlaştırıldığı" incelenmek istenmiştir. Bu amaçla, 2, 293, 531 kayıtlı kullanıcı sayısı bulunan, 6 farklı ülkede "Tweege" ismiyle yayınlanan Tipeez Çocuk ve Gençlik Portalı, popüler bir çocuk sitesi olması nedeniyle inceleme için seçilmiştir. Ayrıca söz konusu sitenin seçilmesinin bir diğer önemli sebebi, ana akım medyada da geniş bir ulaşım ağına 
sahip olan Doğan Yayın Grubu'na ait olmasıdır. Sitenin ana sayfasında sitenin kuruluş amacının sitede yayınlanan içerikle "çocuklara eğlence ve bilgi sunulmak" olduğu belirtilse de sitenin asıl amacının "çocukları tüketici bir yurttaş" haline dönüştürmek olduğu düşünülmektedir. Dolayısıyla çalışmada "çocuklar site aracılığıyla tüketime nasıl alıştırılıyorlar?" sorusundan hareket ederek aşağıdaki araştırma sorularına yanıt aranmaya çalışılmıştır:

1. Sitenin genel olarak yapısal özelliklerinin tümünde (menüde yer alan araçlar içinde; oyunlar, haber, forum gibi) tüketim ideolojisini destekleyen hangi unsurlar bulunmaktadır?

2. Çocukları eğlendirmeye, bilgilendirmeye yönelik olarak hazırlandığı söylenen site içerikleri hangi amaçlara yönelik olarak hazırlanmıştır?

Sitede çocuklara yönelik aktiviteler nelerdir? Bu aktiviteler içinde tüketim kültürüne aşinalık kazandıran hangi pratikler bulunmaktadır?

3. Çocuklara yönelik olarak sitede yer alan haber kategorileri nelerdir?

Çocuklara yönelik haber kategorileri içinde tüketim kültürüyle ilgili olan haberler hangi oranda bulunmaktadır?

4. Çocukları bilgilendirmeye yönelik olarak hazırlanan haber içeriğinin söylemi tüketim ideolojisini nasıl pekiştirmektedir?

Haberlerin söylem üretiminde hangi tüketim stratejilerinden faydalanılmıştır?

Çalışmada, sitenin göze çarpan tüketim pratiklerinden bahsedilmiş ancak sitenin yapısal olarak geniş bir içeriği bulunması (haber, oyun, forum, reklam gibi) nedeniyle çalışma sadece sitede yayınlanan haber incelenmesiyle sınırlandırılmıştır. Ayrıca, site incelendikçe sitede rastlanan "reklam" kısmında firmaların çocuklara yönelik reklam stratejileriyle büyük küresel firmaların nasıl pazarı haline geldiğinin anlatıldığı görülmüştür. Bununla birlikte, pazarlama stratejilerinin toplumsal cinsiyete özgülenen bir yapıda olduğu da tespit edilmiştir. Fakat daha kapsamlı bir çalışma için bu iki konu başka bir çalışmaya bırakılmışıı. Çalışma kapsamında, sitede 2011-2017 yılları aralığında toplam 500 haber olduğu görülmüştür. Bu haberler içinden tüketim unsuru barındırması nedeniyle 146 haber içerik analizi yöntemiyle incelenmiştir. Dolayısıyla, tüketim kültürüyle ilişkilendirilemeyen içerikler konu dışı tutulmuştur. Tüketim söylemine sahip 146 haber içinden araştırma sorularına en iyi yanıt alabileceğimiz 10 haber, amaçlı örnekleme tekniğiyle seçilmiştir. Sitedeki haberlerin analizinde araştırma soruları doğrultusunda nicel bir araştırma yöntemi olan içerik analiziyle, nitel bir araştırma tasarımını yansıtan söylem analizi birlikte kullanılmıştır. Sitede yer alan tüketim kültürüne ait söylem, ideolojik bir söylem olarak düşünülmüştür. Bu bakımdan inceleme için seçilen haberler Van Dijk'in söylem analizindeki "makro yapıyı oluşturan "tematik ve şematik" yapı örgüsünden yola çıkılarak çözümlenmiştir. Dolayısıyla haber söylemi incelenirken haberin başlığı, girişi, spotu, haber metni, yorum ve bağlam bilgisinden yararlanılarak bir çözümlemeye gidilmiştir. Haber metinleri aşağıdaki araştırma sorularından hareket edilerek çözümlenmiştir:

1. Haberler reklam ya da ilan metni şeklinde mi yazılmıştır?

2. Haberlerde ulusal veya küresel firmalara ilişkin hangi bilgiler, nasıl sunulmuştur? 
3. Haber metinlerinin altında çocukların interaktif olarak katılımını sağlayan araçlar kullanılmış mıdır? (Yorum ya da link gibi)

4. Haberlerin hitap ettiği (ulaşmak istediği) kitle kimdir?

5. Haberin okuyucuları olarak çocuklar nasıl konumlandırılmışlardır?

6. Haberlerde çocuklar ürün almaya özendirilmekte midirler?

7. Haber metinlerinde çocukların ürüne aşinalık, marka farkındalığı ya da bağımlılık kazanmaları için hangi stratejiler kullanılmıştır?

8. Haberlerde popüler yıldızlar, çizgi film kahramanları gibi tüketim idollerinden faydalanılmış mıdır?

\title{
3. “Tipeez Bizim Yerimiz" Sitesi Üzerinden Tüketim Kültürü Unsurları'nın Analizine İlișkin Bulgular
}

\begin{abstract}
"Tipeez Bizim Yerimiz" isimli çocuk sitesinin ana sayfanın genel görünüşüne bakıldığında, sitenin en üst kısmında ana menü bulunduğu görülmektedir. Menüde, "Benim Dünyam", "Tipeez Dünyası", "Oyunlar", "Haberler", "Forumlar", "Çizgi Filmler", "Tipstar", "Hopsohbet” ve "Tipeez Dükkan" kısımları yer almaktadır. Menünün hemen yanında üye kullanıcı sayısı, çevrimiçi kişiler ve üye girişi yer almaktadır. Ana menünün altında Tipeez'in logosu bulunmaktadır. Orta sayfada haberler menüsünde yayınlanan haber başlıkları, haber başlıklarının altında ise "Hürriyet Çocuk Kulübü", "Süt Eşleștirme", "Fotoğraf", "Kasa Oyunu", "Forumlar" ve "TipeezDünyası”na giriş linkleri yer almaktadır. Sitenin üst kısmında "Benim Dünyam" kısmı yer almaktadır. Benim Dünyam, "tipimi düzenlemek istiyorum", "yeni fotoğraf yükle", "bilgilerimi güncelle", "çılgın mesaj gönder", "blogum" ve "arkadaşlarım" kısımlarından oluşmaktadır. Siteye üyelik bu bakımdan yetişkinlere yönelik hazırlanmış sosyal paylaşım sitesi olan "facebook" iletişim ağını anımsatmaktadır.
\end{abstract}

Tipimi düzenleme sekmesinde üyelere saç ve göz renklerini değiştirebilecekleri, çeşitli aksesuarlar alabilecekleri, farklı tarzlara sahip olabilecekleri giysi setleri hazırlanmıştır. Çocuklar mağazanın vitrinlerini gezerek alış-veriş yapar gibi hangi ürünleri indirimli ve kaç puan karşılığında alabileceklerini öğrenmektedirler. Yine sitede, para anlamına gelen "puan" karşılığında bu giysi setlerine kavuşabilecekleri söylenmektedir. Yeterli puan bakiyesi olmayan çocuklar "TipeezDükkan"dan 3TL karşılında 100 puan, 6 TL karşılığında 250 puan, 10 TL karşılığında 500 puan, 15 TL karşılığında 1000 puan alabilmektedirler. Yine benzer bir şekilde siteye kayıt aşamasında da "cep telefon numarası" gibi özel bilgiler verildiği takdirde "tippuan" kazanılacağı belirtilmiştir. Tipimi düzenleme oyunu, puanların para karşılığında alınması üzerine kurulu bir oyundur. Böylece, oyun oynamanın masumiyeti, çocuktan oynadığı oyun karşılığında para kazanma beklentisiyle yitirilmiş olmaktadır.

Sitede yer alan "Tipstar" kısmı da çocuklara popüler olmanın yollarını göstermesi bakımından önemli bir kısımdır. Tipstar kısmı "Bahar Tipi", "Bayram Evi 2015", "Tipeez Video Yarışması", "Ünlüler Geçidi” bölümlerinden oluşmaktadır. Tipstar kısmında çocuklara hem kendi tiplemelerini hem de ünlülere ait tiplemeleri yine Tipeez Dükkan'dan satın aldıkları giysi setleri aracılığıyla kendi tarzlarını oluşturmaları veya ünlü sanatçıların tarzlarını taklit ederek tiplemeyle ünlü arasında bir benzerlik-ilişki 
kurmaya zorlanmaktadırlar. Tarz ve stil sahibi olmanın sitede işlenen en güçlü tema olduğu tespit edilmiştir. Çocuklar daha küçük yaşlardan itibaren giydikleri kıyafetten, evlerinde kullandıkları mobilyalara kadar seçtikleri nesneler yoluyla kendilerini ifade edebilecekleri fikri yerleştirilmektedir. Site içerisinde sanal bir dükkânın bulunması, mağazanın gerçek yaşamda olduğu gibi indirim, fırsat ürünler sunması, çocukların kapitalist pazar mantığını önceden tanıyıp aşina olmasına neden olmaktadır. Ayrıca, az bir ücret karşılığında bile olsa puan karşılığında ürüne sahip olma fikri, gelecekte çocukları "tüketici yurttaşları" olarak hazırlamaktadır.

\subsection{Sitede Yer Alan Haberlerin İçeriğine İlișkin Bulgular}

Sitede yayınlanmış haber kategorilerine bakıldığında bu haberlerin "Bilişim ve Teknoloji Dünyasındaki En Yeni İcatlar", "Arkadaşlık Tavsiyeleri ve En Son Moda Haberleri", "Magazin Haberleri ile Ünlülerden Son Haberler", "Sanal Alem Hakkında En İlginç Bilgiler ve Haberler", "Uzay Bilimi ve Çevre ile İlgili Haberler”, "En Güncel Haberler ve Tüm Tipeez Haberleri” gibi kategorilerinden oluştuğu belirlenmiştir. Sitede çocuklara yönelik hazırlanan haberlerin "Vızıltı Kanalı" başlığı altında verildiği ve bu haberlerin Tipeez'de yer alan sanal karakterler aracığıyla hazırlanıp yayınlandığı görülmüştür. "Vızıltı Kanalı"nda "bilim teknik" alanında Rüzgar, "ilişki ve moda" alanında Kayla, "magazin haber" alanında Aişa, "sanal alem" alanında Link, "bilim ve çevre" haberlerinde Profezor, "güncel haber" ve "Tipeez haberleri" alanında Bay Tipeez lakaplı site yöneticileri haber yayınlamıştır.

Tablo 1: Haberlerin Yorum Alma Sayısı

\begin{tabular}{|l|l|l|l|}
\hline Haberin Adı & Yayınlanma Tarihi & Etiketler & Yorum Alma Sayısı \\
\hline Okulda Ne Kadar Popülersiniz? & 24.10 .2011 19:00:15 & $\begin{array}{l}\text { Dersler, Topluluklar, Arkadașlar, } \\
\text { Güzellik-Bakım, Öğretmen }\end{array}$ & 729 \\
\hline İnternet Bağımlılığı & 08.04 .2013 20:00:00 & $\begin{array}{l}\text { Güvenli İnternet, Bilgisayar, } \\
\text { İnternet, Güvenlik, Internette } \\
\text { Güvenlik }\end{array}$ & 393 \\
\hline $\begin{array}{l}\text { Sizin Süper Kahramanınız } \\
\text { Hangisi? }\end{array}$ & 30.07 .2013 18:00:00 & $\begin{array}{l}\text { Yaratıcı Fikirler, Eğlence, Komik } \\
\text { Haberler, Eğlenceli Haberler }\end{array}$ & 384 \\
\hline
\end{tabular}


Tablo 2: Haber Kategorileri'nin Yüzdelik Sırasına Göre Yeri

\begin{tabular}{|c|c|c|c|c|c|}
\hline $\begin{array}{l}\text { Vızıltı Kanalı } \\
\text { Yöneticilerinin } \\
\text { İsimleri }\end{array}$ & Haber Kategorileri & $\begin{array}{l}\text { Yayımlanan Haber } \\
\text { Sayısı (F) }\end{array}$ & $\begin{array}{l}\text { Geçerli } \\
\text { Yüzde }\end{array}$ & $\begin{array}{l}\text { Tüketim } \\
\text { Unsuru } \\
\text { Tașıyan Haber } \\
\text { Sayısı (F) }\end{array}$ & $\begin{array}{l}\text { Geçerli } \\
\text { Yüzde }\end{array}$ \\
\hline Rüzgar & $\begin{array}{l}\text { Bilișim ve Teknoloji } \\
\text { Dünyasındaki En Yeni } \\
\text { İ́catlar }\end{array}$ & 100 & $\% 20$ & 38 & $\% 26,02$ \\
\hline Link & $\begin{array}{l}\text { Sanal Alem Hakkında En } \\
\text { İlginç Bilgiler ve Haberler }\end{array}$ & 100 & $\% 20$ & 25 & $\% 17,12$ \\
\hline Bay Tipez & $\begin{array}{l}\text { En Güncel Haberler ve } \\
\text { Tüm Tipeez Haberleri }\end{array}$ & 100 & $\% 20$ & 25 & $\% 17,12$ \\
\hline Kayla & $\begin{array}{l}\text { Arkadașlık Tavsiyeleri ve } \\
\text { En Son Moda Haberleri }\end{array}$ & 100 & $\% 20$ & 26 & $\% 17,8$ \\
\hline Aișa & $\begin{array}{l}\text { Magazin Haberleri ile } \\
\text { Ünlülerden Son Haberler }\end{array}$ & 100 & $\% 20$ & 21 & $\% 14,3$ \\
\hline \multirow[t]{2}{*}{ Profezor } & $\begin{array}{l}\text { Uzay Bilimi ve Çevre ile } \\
\text { İlgili Haberler }\end{array}$ & 100 & $\% 20$ & 11 & $\% 7,53$ \\
\hline & Toplam: & 500 & $\% 24$ & 146 & $\% 99,89$ \\
\hline $\begin{array}{l}\text { Missing Value } \\
\text { (Kayıp Değer) }\end{array}$ & & & & & $\% 0,11$ \\
\hline
\end{tabular}

Vızıltı haber kanalı kategorisinde karşımıza çıkan içerikler bizzat kanal yöneticileri tarafından makale ismi ile adlandırılmaktadır. Tipeezciler'e zekice yorumlar yapmalarını tavsiye eden kanal yöneticileri, bu yorumların makalenin altında görüleceğini söylenerek yapılan periyodik kontrollerde zekice yorumlar için 150 sanal puan (Tippuan) verdiklerini belirtmektedir. Ayrıca kazanılan bu puanlarla, çocukların Tipeez Dünyası'ndaki evlerini dekore edebildiklerine dikkat çekilerek, tiplerine uygun eşyalar alabildikleri ve tiplerini düzenleyebildikleri ifade edilmektedir. Haber kategorilerine bakıldığında toplam haberlerin yüzde 24'lük bir kısmında tüketim kültürü unsurlarına rastlanmıştır.

\subsection{Sitede Yer Alan Haberlerin Söylemine İlișkin Bulgular}

Çocuklara eğlenceli gelmesi muhtemel fakat çocuğun gelişimini tetiklemesi muhtemel olmayan çocuklara yönelik pazarlama etkinlikleri içeren haber-reklam türündeki haberlerin, markaların hoşa giden imgelerini yaratmak amacından başka bir şeye hizmet etmediği görülmüştür. Haber-reklam türüyle çocuklar, medya endüstrisinin bir parçası haline getirilmekte, haber metinlerinde verilen tüketim mesajları sayesinde reklamı yapılan ürünü almaya özendirilmekte ya da en azından çocukların ürüne karşı sempati geliştirmeleri amaçlanmıştır. İncelenen haberlerin önemli bir kısmında sadece 
dış kıyafetle sınırlı kalınmamış, bu kıyafet kombinleri, çanta, ayakkabı, saat, gözlük, aksesuar gibi tamamlayıcılar ile bir bütün olarak satılmaya çalışılmıştır.

Özellikle ünlü kişilere yer verilmesi nedeniyle, tasarım ürünlere ve Türk pazarına girmemiş yurtdışı markalarının sıklıkla yer aldığı haberlerde, yaşam tarzının da bir parçası olan bakım, aktüel, seyahat, yemek, dekorasyon gibi unsurlara da odaklanıımıştır. Bunların yanı sıra, kıyafet kombinlerinin genel olarak kanal yöneticileri tarafından sunulduğu haberlerde, haber metinlerin fotoğraflara göre daha arka planda kaldığı tespit edilerek çok sık olmamakla birlikte videoların da kullanıldığı ve marka-ürün isimlerine sıklıkla yer verildiği saptanmıştır. Bu yolla, sitede yer alan haber içerikleriyle çocukların algı, istek, arzu ve intiyaçlarını şekillendirebilme ve etkileyebilme gücü olacağı varsayılmıştır.

Tüketim pratikleri ve hayat tarzlarına odaklanan haber içerikleri incelendiğinde, yeni medyanın çocukları"özgür bir birey” olarak kabul gördüğü varsayımı yerine firmaların pazarlama stratejisi olarak kullanıldığı bir araç olarak kaldığı ortaya çıkmıştır. Çocukların sitede kendilerine yönelik olarak sunulan haber içerikleriyle çevrelerindeki ve dünyada olup bitenler hakkında haberdar olmak ve yeni bilgiler edinmek yerine, popüler olan ürünler ve yeni tüketim pratikleri hakkında bilgilendirilerek "potansiyel müşteriler" haline dönüştürüldükleri tespit edilmiştir.

\section{Haber Çözümleme 1:}

\section{Başlık: "Yepyeni Sütaş Büfe Ürünleri ile Tanışın!”}

Başlıktan da hemen anlaşılacağı üzere bu haber, reklam-haber türündedir. Haber metninde Sütaş Büfe'de yer alan ürünlerle ilgili açıklama yapılmaktadır. Rüzgar, Nisan 2016'da yapılan TEOG partisine katılan arkadaşlarına seslenerek, Sütaş Büfe'ye birbirinden güzel ve ilginç ürünler eklendiğini belirtmekte ve ürünleri görmek isteyenler için link vermektedir. Haberde doğrudan Sütaş firmasının yeni ürün gamındaki ürünlerin reklamını yapmaktadır. Tüketim söylemi haberin metnine gizlenmemiştir ancak haber kategorisi altında yapılması, çocukların reklamla haber arasındaki ayrımı anlayacak bir bilişte olmamaları sebebiyle onları birer av haline getirmektedir. Haberin sonunda, ürünlerin altına linkler yerleştirilmesi, siteyi kullanan çocukların potansiyel müşteri olarak görüldüğünün bir delilidir.

\section{Haber Çözümleme 2:}

\section{Başlık: "Her Okula Minecraft!"}

Haber metninde çocuklar için oldukça popüler olan Minecraft firmasının yeni bir ürününün eğitim alanında nasıl kullanılacağı anlatılmaktadır. Haberde, 2014 yılında yapımcı firma Mojang'ın, 2.5 milyar dolara Minecraft'ın haklarını satın aldığından bahsedilerek Microsoft'un Minecraft: Education Edition yani eğitim sürümünü dünya çapındaki tüm okullara yayarak bir ders aracı olarak kullanmayı planladığı belirtilmiştir. Haberin sonunda Tipeez kullanıcılarına, Microsoft Minecraft: Education Edition sisteminin ülke çapında da hayata geçmesini isteyip istemedikleri sorulmaktadır. 
İlk sürümünden beri güncellenmeye devam eden Minecraft oyunu, küplerle çeşitli tasarımlar yapmanızı sağlayan 3 boyutlu bir oyun olarak karşımıza çıkmaktadır. Haber metninden anlaşıldığı üzere, Minecraft firması oyunlarının eğitim versiyonuyla, ilk ve orta öğretim okullarında okuyan öğrencileri hedef-kitle olarak seçmiştir. Böylece sitede yer alan bu haber aracılığıyla firma ve firmanın hedef-kitle olarak seçtiği ilgili yaş aralığındaki çocuklar buluşturulmuştur. Haberin sonunda çocuklara bu oyunu isteyip istemediklerinin de sorulmasıyla hedef-kitle olarak düşünülen yaş grubundaki çocuklardan anında feedback (geri bildirim) almanın en hızlı, maliyetsiz ve güvenilir yolu bulunmuştur.

\section{Haber Çözümleme 3:}

\section{Başlık: "Ruh Halinizi Çantanızda Taşıyın!"}

Rüzgâr tarafından yapılan haberde, kent yaşamı içinde kullanımı oldukça rahat olduğu söylenen "Backpaix" marka bir sırt çantası tanıtımaktadır. Ürün tanıtım haberciliği kategorisinde değerlendirebileceğimiz haber, markanın imaj haberi olarak karşımıza çıkmaktadır. Sırt çantasının ayakkabı gözü, bilgisayar ve tablet için yan cep, harici şarj cihazı gibi detaylara sahip olduğu aktarılarak hayatın her noktasına entegre olunabileceği mesajı verilmek istenmiştir. Ayrıca, çantanın ön yüzünde bulunan Smart Badge ismindeki rozetlerle, ileriki zamanlarda akıllı telefon bağlantısıyla kişiselleştirilebileceği ve belirli durumlara karşı bildirim merkezine dönüşeceği bilgisi de paylaşılmıştır. Çocukların hedef-kitle olarak seçildiği reklam haberde, çocuklara sadece $\mathrm{x}$ marka bir ürün satmak değil ama aynı zamanda $\mathrm{x}$ marka ürüne ait çanta ve rozetle kişisel cep telefonlarına bağlanabilecekleri yeni bir tüketim alışkanlığı da kazandırmak istenmiştir. Çocuklar böylece gündelik yaşamlarında kullandıkları $x$ marka ürünler aracılığıyla kendilerini ifade edebilmenin yeni bir yoluyla tanışmışlardır.

\section{Haber Çözümleme 4:}

\section{Başlık: "Kendi Kendine Bağlanan Ayakkabı"}

Haberde: akıllı saat, akıllı gözlük gibi akıllı ayakkabıların da gündelik yaşamda kalıcı bir yer edineceği iddia edilmiştir. Haberin devamında, 1989 yılında çekilen "Geleceğe Dönüş" filminde hayal edilen, bağcıkları kendi kendine bağlanan ayakkabının gerçek olmasından bahsedilmektedir. Bu reklam-haberde ürünlerin satışı için sıkça başvurulan yöntemlerden biri olan daha önce herkes tarafından bilinen, sevilen ve yaygınlaşan popüler ürünlere gönderme yapılmıştır. 80'li yıllarda çocuk ve gençlerin en sevdiği filmlerden biri olan "Geleceğe Dönüş" filmine bir gönderme yapılarak ayakkabı bağıyla filmdeki ayakkabı bağı arasında bir çağıışım ilişkisi kurulmak istenmiştir. Böylece, çocuk ve gençler arasında popüler olan metinler üzerinden ürünler popüler hale getirilmeye çalışılmıştır. Yaşam tarzına, modaya nasıl ayak uydurulacağı ya da takip edileceğine ilişkin içeriklerin aktarıldığı bu haberlerde, modanın takip edilmesinin ve diğerlerine aktarılmasının önemi vurgulanmıştır. 


\title{
Haber Çözümleme 5:
}

\author{
Başlık: "Sevgililer Gününüz Kutlu Olsun!"
}

Sitede yer alan haberler incelendiğinde haberlerin sadece ürün ve markaların reklamını yapmanın değil ama aynı zamanda çocuklara yetişkinlerin tüketim kültürü ritüellerinin de öğretilmesi yolunun açıldığı tespit edilmiştir. Kayla tarafından hazırlanan haber metnine bakıldığında çocuklara, sevgililer gününde "tip"lerini daha sevgi dolu yapmaları ve sevgililer günü için süslenme teması oluşturmaları istenmiştir. Haberin devamında Sevgililer Günü'nün evrensel bir değer olduğu vurgulanarak, Tipeez'deki sevgi dolu kıyafetleri hem kızların hem de erkeklerin kullanabildiği belirtilerek, o güne özel aksesuar ve hediyelerin unutulmaması gerektiği öğütlenmiştir. Böylece, çocuklara daha küçük yaşlardan itibaren güne özel hediye alma, eğlence ve giyinme pratikleri oynama benimsetilmek istenmiştir.

\section{Haber Çözümleme 6:}

\section{Başlık: "Kızının Odasını Disney Dünyasına Çevirdi!"}

Haberde, illüstratör Jennifer Treece'in, kızının odasını onun en sevdiği Disney filmi olan Rapunzel temasıyla değiştirdiği bilgisi verilmektedir. Çocuğun gözünde hayali bir karakterin nasıl popüler ve vazgeçilmez hale gelebildiği meşrulaştıran haber, Disney konseptli çizimler yapan "anne Treece'in kızını rüyalarıyla buluşturduğu" sloganı işlenmektedir. Böylece haber sayesinde, hem küçük kızların hayallerinin Disney prenseslerinden biri olabilme vurgusu hem de bu hayalin ebeveynler tarafından da desteklemesi gerektiği düşüncesi bizzat gerçek yaşamda başarılı bir illüstratör olan ünlü bir anne tarafından onaylatılmıştır.

\section{Haber Çözümleme 7:}

\section{Başlık: "Okulda Ne Kadar Popülersiniz?"}

Misafir muhabir Bonbon kız kullanıcısının hazırladığı haberde, popüler olmanın ilk koşulun kişisel bakımdan geçtiği belirtilmektedir. Ayrıca okula temiz bir şekilde gidildiğinde başta öğretmenler olmak üzere birçok kişinin dikkatinin çekilebileceği söylenerek, okulda başarılı olmanın ün getireceği ifade edilmiştir. Çantaya rozetler takmanın, defter ve kitaplara çıkartmalar yapıştırmanın, ayakkabının, çantanın, kalem kutusunun uyumlu ve popüler olmasının önemine değinilen haberde, bu yolla çocukların popülerliğe daha çok yaklaşabilecekleri ifade edilmiştir. Haber aracılığıyla çocuğun ötekilerle kurduğu ilk iletişim biçimi, fiziksel görünüşü üzerinden yani kıyafetleri aracılığıyla ve kıyafetin taşıdığı sembolik anlamlar üzerinden gerçekleşeceği fikri ekilmek istenmiştir. Tüketim ideolojisi tarafından pompalanan güzellik algısı özellikle de genç kızların ve kadınların kendisiyle ilgili olarak çarpıtılmış beden algısına sahip olmasına neden olmaktadır. Bu haberle birlikte çocuklar görünüşe bağlı bir "popülerlik" üzerinden ileride kendilerine ilişkin beden algılarının ne olabileceğinin yolu açılmıştır. Böylece haber metnini okuyan çocuklar, büyüdüğünde görünüşünün kendisine beğeni ve başarı getireceği fikrine hazırlanmışlardır. 


\section{Haber Çözümleme 8:}

\section{Başlık: "Yapay Et 6 Ay Sonra Raflarda"}

Sanal karakter Profezor'un sayfasında yayınlanan "Yapay Et 6 Ay Sonra Raflarda" isimli haberin spotunda, çiğ etlerden elbise yaptırarak bir davete katılan Lady Gaga'nın hayvan severlerden büyük tepki aldığı belirtilerek artık hiçbir hayvanı kesmeye gerek kalmadan et üretilebileceği açıklanmaktadır. Gelecekte yiyecek sıkıntısından endişelenen bilim insanlarının kök hücreden et üretimine başladığını anlatmak için, ünlü bir pop müzik şarkıcısı olan Lady Gaga'nın giydiği kıyafet üzerinden söz konusu konuya dikkat çekilmek istenmiştir. Bilim alanında gelişmeler neticesinde, "et üretimiyle" ilgili bir konuyla ilgili haber yapılırken bile popüler bir ikonun kullanılmış olması, popüler idoller aracılığıyla çocuklara popüler kültür ve onun ürünleriyle erken yaşta tanışma ve alışma imkânı vermektedir.

\section{Haber Çözümleme 9:}

\section{Başlık: "Tipeez’in Stil İkonları!"}

Tarz ve stil sahibi olmanın güçlü bir tema olarak işlendiği sitede bu haberle birlikte "tarz ve stil sahibi olma" söylemi en belirgin halini almıştır. Sanal karakter Kayla tarafından hazırlanan haberin spotunda, kızlara kendine has kıyafet ve kombinlerle nasıl stil oluşturabilecekleri anlatılmıştır. Haberin devamında Tipeez kızı olabilme şartının modaya uymaktan geçtiği vurgulandığı için, kızların hangi tarz stilleri oluşturulabileceklerine ilişkin ipuçları sunulmuştur. Sunulan bu stiller genç kızlara görünüşleriyle birlikte hangi özelliklere sahip olabileceklerini göstermektedir. Buna göre siteye abone olan kız çocuklar "rengarenk, popçu, günlük şıklık, günlük spor, taraftar ve diğer" olmak üzere genel kategoriler etrafında belirlenmiş klişelerden birini seçerek bir profil oluşturabileceklerdir. Kız çocuklara önerilen farklı aksesuar ve kombinlerle kızların tarzlarının neler olabileceği tanımlanırken, aynı zamanda her bir stil kızların sahip olduklarını düşünmelerini sağlayacak bir kişilik özelliğiyle somutlaşmıştır. Kanal yöneticileri tarafından kız çocuklara giydirilen bu stereotipler, gerçekte çocukların kendi potansiyellerini keșfetmelerine izin vermemektedir.

Tablo 3: Habere Göre Popüler Stiller ve Stille Sahip Olunacak Özellikler.

\begin{tabular}{|l|l|l|}
\hline Stil & Stilin Göstergesi: & Stilin Sunduğu Özellikler: \\
\hline Rengarenk & $\begin{array}{l}\text { CIvıl cıvıl, rengarenk kombinler, renkli saçlar, } \\
\text { renkli saçlara uygun olarak seçilen renkli giysi } \\
\text { ve aksesuarların tercih edilmesi. }\end{array}$ & Sevecen ve șarkı tutkunu kișiler. \\
\hline Popçu & $\begin{array}{l}\text { CIvıı cıvıl, rengarenk kombinler, renkli saçlar, } \\
\text { renkli saçlara uygun olarak seçilen renkli giysi } \\
\text { ve aksesuarların tercih edilmesi. }\end{array}$ & $\begin{array}{l}\text { Șarkı dinlemeyi ve söylemeyi sevenler. Ileride } \\
\text { ünlü olmak isteyenler. }\end{array}$ \\
\hline
\end{tabular}




\begin{tabular}{|l|l|l|}
\hline Günlük Șık & $\begin{array}{l}\text { Günlük hayatta kullandıkları kıyafetlerin tercih } \\
\text { edilmesi. }\end{array}$ & Arkadaș canlısı olanlar. \\
\hline $\begin{array}{l}\text { Günlük } \\
\text { Spor }\end{array}$ & $\begin{array}{l}\text { Günlük hayatlarında daha çok spor kıyafetlerin } \\
\text { tercih edilmesi. }\end{array}$ & En az bir spor dalılla ilgilenenler. \\
\hline Taraftarlar & $\begin{array}{l}\text { Tutulan takımın renklerinin, formasının kıyafet } \\
\text { olarak tercih edilmesi. }\end{array}$ & Takım taraftarı olanlar. \\
\hline $\begin{array}{l}\text { Diğer } \\
\text { Tarzlar }\end{array}$ & $\begin{array}{l}\text { Diğer kategorilerdekilerden farklı olarak bir } \\
\text { alanda beceri ve uzmanlık gösterecek kișilerin } \\
\text { kıyafet ve aksesuarlarının tercih edilmesi. }\end{array}$ & $\begin{array}{l}\text { Fantastik, blogger, youtuber, vegan, oyun ustası, } \\
\text { bilim tutkunu olanlar. }\end{array}$ \\
\hline
\end{tabular}

\section{Haber Çözümleme 10:}

\section{Başlık: "Sizin Süper Kahramanınız Hangisi?"}

Bay Tipeez tarafından hazırlanan "Sizin Süper Kahramanınız Hangisi?" isimli haberde özellikle erkek çocuklar arasında popüler olan süper kahramanlar hatırlatılarak haber aracılığıyla yeniden popülerleştirilmektedir. Haberde, süper kahramanların her sene olduğu gibi bu sene de San Diego'daki "Comic-Con" etkinliğinde bir araya geldikleri bilgisi spota taşınmıştır. Haberin devamında binlerce süper kahraman hayranının birbirinden ilginç kostümlerinin yer aldığı fuara yoğun ilgi gösterdiği belirtilmekte ve Spider-Man'den, Blade'e; Iron Man'den, Fantastic Four'a birçok süper kahramanın hayranlarından tam not aldığı ifade edilmektedir. Haberin sonunda kullanıcıya, süper kahramanının hangisi olduğu sorulmaktadır.

Çizgi film kahramanlarıyla özdeşleşen çocukların yaşamlarını kendi perspektiflerine göre yeniden oluşturdukları düşünüldüğünde, çizgi film kahramanları tarafından yaratılan dünyada hayallerini gerçekleştirerek bir kontrol duygusu yaşadıkları söylenebilmektedir. Çocuklara her zaman kazanma ve güçlü olma hissini yaşatan süper kahramanlar, taklit ve karakter oyunlar sayesinde, çocuklara kim olmak istiyorlarsa onu olabilme imkânını vermektedir. Bu bağlamda, yaratılan kültür ile kurguladığı anlam dünyasında bir takım stereotipler yaratılarak çocuklar tüketim ideolojisine yöneltilmiş ve onu yapay bir çevrede biçimlendirmiştir. Özdeşleşme ile çocuk, sunulan stereotipler ve kimlikler ile bütünleştirilme çabasındadır. Örümcek adam kostümleri giyen, yeni çıkan örümcek adam aksesuarlarını isteyen ve örümcek adamla ilgili her şeyi seven ve alan çocuklar, yeni medyada da süper kahramanlar aracılığıyla tüketim kültürünün nesnesi haline getirilmektedirler.

\section{Sonuç}

Çocuklara yönelik bilgi, eğlence, oyun ve kültürel içerik sunduğu iddiası taşıyan web siteleri de küreselleşen tüketim kültürünü, çocukların gündelik yaşamlarının bir parçası haline getirmektedir. Tipeez'de yer alan içerik, çocuklara nesnelere sahip olarak bir dünyaya sahip olabilme yollarını öğreterek henüz erken yaşlarda tüketim pratikleri yapabilecekleri bir mecra simülasyonu yaratmıştır. Sitenin popüler ürünler, şarkıcılar, programlar, filmler aracılığıyla "ünlü" ve "popülerlik" kavramının daha küçük 
yaşlarda öğretilmesine hizmet ettiği görülmüş ve "tipstar”, “ünlü oyunları", ünlü yabancı şarkıcılardan haberler, Tipeez'de yer alan karakterlerin rozet, bardak, tişörtlerinden oluşan tipeez mağaza gibi köşeler ile çocuklar tüketim kültürüne alıştırılmaya başlanmıştır. Popüler olanın yüceltildiği ve değerli kılındığı sitede "tip" yani "görünüş" çocuklar için bir takıntı biçimine dönüşmüş, çocuklar tarz ve stile de karşılık gelen "tip"leri konusunda site içinde diğer çocuklarla rekabete teşvik edilmişlerdir.

"Tipeez Bizim Yerimiz" sitesi, kullanıcısı olan çocuklara, akran grubu ilişkilerinin merkezinde olduğu bir dönemde, diğer çocuklarla olan etkileşimlerinde "marka farkındalığı ve bağlılığı" üzerinden iletişim kurabilecekleri bir içerik sunmaktadır. Böylece çocuklar, ürünlerin kullanımında diğer çocuklar tarafından teşvik edilmekte, onların beğeni ve yorumlarından etkilenmeye daha açık hale gelmektedirler. Bu durum haberler altına yorum yapabilme özelliğiyle desteklenmiştir. İncelenen haberlerin birçoğunda yeni ürünlerle ilgili çocukların görüşlerini alabilecekleri "link ve yorum yapabilme" araçları yer almaktadır. Firmalar bu yolla ulaşmak istediği çocuk hedefkitleye bu araçlar vasıtasıyla doğrudan hızlı ve maliyetsiz bir şekilde ulaşabilmektedir.

Sitede çocuklara yönelik hazırlanan haber içerikleri çocuklar tarafından değil sanal karakterler altında site yöneticileri tarafından hazırlanmaktadır. Bu bağlamda, haber içeriklerine bakıldığında genellikle reklam-haber türü bir içeriği sahip olduğu söylenebilir. Çocuklar yetişkinler gibi reklam ile haber arasındaki ayrımı bilmemekte dolayısıyla ulusal ve küresel ölçekteki firmaların "açık av" olarak gördükleri bir hedefkitle haline gelmektedirler. Reklam-haber türü gibi çocukların potansiyel müșteriler olarak konumlandırıldıkları haber içeriğiyle birlikte sitede çocuklara yeni tüketim alışkanlıkları kazandırmaya yönelik stratejilerin kullanıldığı gizli, örtük haber içeriklerine de rastlanılmıştır. Eşya ve aksesuar kullanımı, özel günlerin kutlanmasına ilişkin ritüeller, popüler idoller (popüler sanatçılar) yoluyla popüler pratikler kazandırma, popüler filmlerin ya da çizgi film karakterlerine yapılan göndermeler gibi haber içerikleri üzerinden çocuklar, tüketime alıştırılmakta, özendirilmektedir. Çocuk yaşlarda edinilen bütün bu pratikler kapitalist pazar endüstrisinde çocukları geleceğin yetişkin "tüketici yurttaş" bireyleri olarak hazırlamaktadır.

Sitenin genelinde "tip" üzerinde bir tarz oluşturma ve herkes tarafından beğenilme "popüler olma" çocuklar için başlıca amaç haline getirilmiştir. Çocuklar hem kendi tiplerini hem de popüler olan yıldızların tiplerini "tippuan" karşılığında düzenlemekte, kendi kimliklerini popüler yıldızlar üzerinden tanımlamaktadırlar. Benim dünyam, tipimi düzenle, tippuan satın al kısımları birer oyun olmanın ötesinde, çocuklara kendilerini aldıkları sanal ürünler üzerinden yansıtabilecekleri bir dünya sunması bakımından tüketim ideolojisini oyunlar aracılığıyla öğretmektedir. Yeni medyada çocuklar, sanal tüketimcilik, neo puan, sanal para birimiyle çeşitli öğeler aracılığıyla, alım-satım yaparak oyun oynamaya özendirilerek tüketmekte ve çocukluğun masumiyetini yitirmektedirler.

Çocuklar, yeni medyada da reklam ve iletişim mesajlarının doğrudan hedefi haline gelmiştir. Çocukları tüketim kültürünün zararlı etkilerinden korumak için televizyon ya da internet mecrasını yasaklamanın artık geçerli bir çözüm olmadığı görülmüştür. Bunun yerine ebeveynlerin çocuklarının yeni medyada nerede ve nasıl vakit geçirdikleri hakkında bilgi sahibi olarak, çocuklarını oyun, haber, eğlence içeriğinin içine sindirilmiş mesajlarla tüketime yönelten web siteleri yerine kişisel gelişimine katkı sunacak 
sitelere yönlendirmeleri daha uygun olacaktır. Diğer taraftan, çocuklar yeni medyada reklam mesajlarına karşı eleştirel bir yaklaşıma sahip değillerdir. Anne ve babalar çocuklarına bu mesajlarla aralarına mesafe koyabilmenin yollarını öğretebilirler. Böylece ebeveynler, çocuklarını yeni medya karşısında savunmasız tek başlarına bırakmamış olacaklardır.

Reklamların zararlı etkilerinden çocukları korumak için devlet yasal önlemler alsa da bazen reklam mesajları sitedeki içerik içine gizlenmiş olabilir, dolayısıyla çocuklara doğrudan görünmeyebilmektedir. İncelenen sitede de görüldüğü üzere hangi içeriğin reklam hangisinin oyun ya da haber olduğu belli değildir. Çocuk reklam-haber ayrımını yapabilecek bilgiye sahip olmayabilir. Dolayısıyla çocuklar, reklam mesajlarını gerçekmiş gibi algılama eğilimindedirler. Bu noktada, ailenin çocuklara bu durumu anlatması kadar okullarda "bilinçli yeni medya" eğitimi derslerinin verilmesi de çocukları tüketici bir av konumundan kurtarmaya yarayabilecektir.

Yeni medyada çocukları korumada "eğitim" ya da "bilinçlendirme tek başına yeterli olmayabilir. Yeni medya alanının da diğer iletişim kanalları gibi düzenlenmesi gereklidir. Yeni medya ne kişilerin ne de ticari firmaların her istediklerini yapabilecekleri bir mecra olmalıdır. Dolayısıyla, amacı sadece tüketici çocuk hedef-kitlesi oluşturmak olan web sitelerinin de yasal olarak sınırlandırılması ve denetlenmesi kaçınılmazdır. Ayrıca, devletin çocuklara yönelik olduğu iddiası taşıyan site içeriklerini izleyip takip edebilecek, bu içeriklerin çocuklar üzerinde etkisini araştıracak uzmanlarla ve iletişim bilimcilerle çalışması tüketim kültürünün çocuklar üzerindeki etkisini denetlemede ve azaltmada başarılı olma şansını arttıracaktır.

\section{Kaynakça}

Aaker, A. David (2002). "The Internet as Integrator: Fast Brand Building in Slow-Growth Markets." Strategy\&Busines (28): 16-21.

Akdağ, Ç. Tuğba (2016). "Yeni Medyada Çocuk Haberciliği: "Milliyet Çocuk, Hürriyet Çocuk ve Cicicee Çocuk Deyince Sayfalarının İncelenmesi." Erişim Tarihi: http://dergipark.gov.tr /download /article-file/265020. 28.03.2017.

Bayzan, Şahin (2016). "Türkiye'de Güvenli İnternet ve Uygulamaları, Bilgi Teknolojileri ve İletişim Kurumu." http://docplayer.biz.tr/30559443-Turkiye-de-guvenli-internet-ve-uygulamalari.html. Erişim Tarihi: 28.03.2017.

Binark, Mutlu ve Bayraktutan Sütçü, Günseli (2008). Kültür Endüstrisi Olarak Dijital Oyun. İstanbul: Kalkedon Yayınları.

Bryce, Robert (2005). "Click and Sell."www.utexas.edu/features/2005/ advertising/index.html. Erişim Tarihi: 21.02.2017.

Buckingham David (2013) "Selling Childhood, Journal of Children and Media." http://dx.doi. org/10.1080/17482790601005017. Erişim Tarihi: 11.03. 2016.

Çakır Hamza ve Yavalar D. Elif (2015). "Geleneksel Çocuk oyunları ve 3-5 Yaş Çocukların Toplumsallaşmasına Etkisi”. Uluslararası Oyun ve Oyuncak Kongresi. Atatürk Üniversitesi Açık Öğretim Fakültesi-Iletişim Fakültesi. Erzurum: Orka Ofset Matbaa. 
Dirimeşe, Erdem (2015). "Dijital ve Mobil oyunların Yabancılaşma ve Sosyalleşme İle ilişkisi". Uluslararası Oyun ve Oyuncak Kongresi. Atatürk Üniversitesi Açık Öğretim Fakültesi-Iletişim Fakültesi. Erzurum: Orka Ofset Matbaa.

Engin, B. Hande (2013). "Çocuk ve Reklam: Çocuklar Olması Gerekenden Erken Büyüyor". Türkiye Çocuk ve Medya Kongresi Bildiriler Kitabı (1), H Yavuzer ve M R Şirin (haz.) içinde. İstanbul: Çocuk Vakfı Yayınları.

Ertürk, Y. Dilek (2011). "Çocukluk Çağı Gelişim Dönemlerine Göre Medya Kullanımı”. Çocuk Hakları ve Medya, Anne-Baba, Öğretmen ve Medya Çalışanları İçin El Kitabı. M R Şirin (haz.) içinde. 1. Türkiye Çocuk Hakları Kongresi. İstanbul: Çocuk Vakfı Yayınları.

Ferrazzi, Keith and Benezra, Robert (2001). "Journey to the Top”. Brandweek. April 16: 28-36.

Giroux, A. Henry and Pollock, Grace (2011). "Is Disney Good for Your Kids? How Corporate Media Shape Youth Identity in the Digital Age". Kinder Culture The Corporate Construction of Childhood inside. Philadelphia: Westview Press. 73-93.

Gülerarslan, Așina (2011). "Tüketici Olarak Çocuk ve Ailenin Satın Alma Kararlarına Etkisi". Selçuk Üniversitesi İletişim Fakültesi Akademik Dergisi. 6 (4): 126-137.

Hazen, Don and Winokur, Julie (1997). We the Media A Citizen's Guide to Fighting For Democracy. New York: New Press.

Lindstrom, Martin and Seybold, B. Patricia (2003). Brand Child: Remarkable Insights in to the Minds of Today's Global Kids \& Their Relationships with Brands. London: Kogan Page Ltd.

Montgomery, C. Kathryn (2000). "Children's Media Culture in the Millennium: Mapping the Dijital Landscape." The Future of Children. Autumn-Winter 10 (12): 145-167.

Montgomery, C. Kathryn (2001). "Digital Kids: The New On-line Children's Consumer Culture." Handbook of Children and the Media. D. G. Singerand J. L. Singer(eds), California: Sage Publication. 635-650.

Moore, S. Elizabeth (2004). "Children and the Changing World of Advertising." Journal of Business Ethics. 52 (2): 161-67.

Murdock, Graham (2015). "Imgesel Kuşatmalar: Dijital Çağda Oyun Oynayan Maddeci Çocuk". Uluslararası Oyun ve Oyuncak Kongresi. Atatürk Üniversitesi Açık Öğretim Fakültesi-Illetişim Fakültesi. Erzurum: Orka Ofset Matbaa.

Polat, H. İsmail (2016). "Dijital-Siber-Sosyal; Yeni Bir Medyadan Yeni Bir Yaşam Alanına Dönüşüm." http://dergipark.gov.tr/trta/issue/23620/252127. Erişim Tarihi: 29.03.2017.

Postman, Neil (1995). Çocukluğun Yok Oluşu. Kemal İnal (çev). Ankara: İmge Kitabevi.

Taylan, Ahmet (2015). "Kültür Endüstrisi Ürünleri Olarak Çizgi Film Ve Oyuncakların Çocuk Ve Ebeveyn Tüketim Davranışlarına Etkisi”. Uluslararası Oyun ve Oyuncak Kongresi. Atatürk Üniversitesi Açık Öğretim Fakültesi-İletişim Fakültesi. Erzurum: Orka Ofset Matbaa.

Tellan, Derya (2015). "Kültürel Dönüşümü Oyun Üzerinden Tartışmak”. Uluslararası Oyun ve Oyuncak Kongresi. Atatürk Üniversitesi Açık Öğretim Fakültesi-İletişim Fakültesi. Erzurum: Orka Ofset Matbaa.

Temür, Nuri (2013). Türkiye'de Güvenli İnternet. Ankara: Türkiye Noterler Birliği Yayınları. 
Timisi, Nilüfer (2011). "Medyada Çocukları Koruyucu Önlemler, Çocuk Hakları ve Medya". AnneBaba, Öğretmen ve Medya Çalışanları İçin El Kitabı. M R Şirin (haz). 1. Türkiye Çocuk Hakları Kongresi. İstanbul: Çocuk Vakfı Yayınları.

TUIK (2013). "06-15 Yaş Grubu Çocuklarda Bilişim Teknolojileri Kullanımı ve Medya." http://www. tuik.gov.tr /PreHaberBultenleri. do?id=15866. Erişim Tarihi: 28.03.2017.

TUIK (2016). "Hane Halkı Bilişim Teknolojileri Kullanım Araştırması." http:// www. tuik.gov.tr/ PreHaberBultenleri.do?id=21779. Erişim Tarihi: 28.03.2017.

"Yepyeni Sütaş Büfe Ürünleri ile Tanışın!" (2016). http://www.tipeez.com/ch/ main/news/ ruzgar/15181/yepyeni-sutas-bufe-urunleri-ile-tanisin.aspx. Erişim Tarihi: 09.03.2017.

"Her Okula Minecraft!" (2016). http://www.tipeez.com/ ch/main/news/ruzgar/ 15138/her-okulaminecraft.aspx Erişim Tarihi: 09.03.2017.

"Ruh Halinizi Çantanızda Taşıyın!" (2016). http://www.tipeez.com/ch/ main/news/ruzgar/15363/ ruh-halinizi-cantanizdan-tasiyin.aspx. Erişim Tarihi: 09.03.2017.

"Kendi Kendine Bağlanan Ayakkabı" (2016). http://www.tipeez.com/ch/main/ news/ruzgar/15524/ kendi-kendine-baglanan-ayakkabi.aspx. Erişim Tarihi: 09.03.2017.

"Sevgililer Gününüz Kutlu Olsun!" (2017). http://www.tipeez.com /ch/main/news/kayla/15966/ sevgililer-gunu-2017.aspx. Erişim Tarihi: 09.03.2017.

“Kızının Odasını Disney Dünyasına Çevirdi!” (2017). http://www.tipeez.com/ch/main/news/ kayla/15986/disney-odalar.aspx. Erişim Tarihi: 10.03.2017.

"Okulda Ne Kadar Popülersiniz?" (2011). http://www.tipeez.com/ch/main/news/tipeez_buzz/6097/ okulda-ne-kadar-populersiniz.aspx. Erişim Tarihi: 10.03.2017.

“Yapay Et 6 Ay Sonra Raflarda” (2011). http://www.tipeez.com/ ch/main/news/tipeez_buzz/5778/ lady-gaga-bu-habere-cok-sevinecek.aspx. Erişim Tarihi: 10.03.2017.

"Tipeez'in Stil İkonları!" (2017). http://www.tipeez.com /ch/main/news /kayla/15975/tipeezmoda-2017.aspx. Erişim Tarihi: 10.03.2017.

"Sizin Süper Kahramanınız Hangisi?" (2013). http://www.tipeez.com/ch /main/news/tipeez buzz/10468/sizin-super-kahramaniniz-hangisi.aspx. Erişim Tarihi: 10.03.2017. 